\title{
Wave Propagation Through Inhomogeneities With Applications to Novel Sensing Techniques
}

\author{
G. Adamovsky, R. Tokars, and D. Varga
}

Glenn Research Center, Cleveland, Ohio

B. Floyd

Sierra Lobo, Inc., Cleveland, Ohio 


\section{NASA STI Program . . . in Profile}

Since its founding, NASA has been dedicated to the advancement of aeronautics and space science. The NASA Scientific and Technical Information (STI) program plays a key part in helping NASA maintain this important role.

The NASA STI Program operates under the auspices of the Agency Chief Information Officer. It collects, organizes, provides for archiving, and disseminates NASA's STI. The NASA STI program provides access to the NASA Aeronautics and Space Database and its public interface, the NASA Technical Reports Server, thus providing one of the largest collections of aeronautical and space science STI in the world. Results are published in both non-NASA channels and by NASA in the NASA STI Report Series, which includes the following report types:

- TECHNICAL PUBLICATION. Reports of completed research or a major significant phase of research that present the results of NASA programs and include extensive data or theoretical analysis. Includes compilations of significant scientific and technical data and information deemed to be of continuing reference value. NASA counterpart of peer-reviewed formal professional papers but has less stringent limitations on manuscript length and extent of graphic presentations.

- TECHNICAL MEMORANDUM. Scientific and technical findings that are preliminary or of specialized interest, e.g., quick release reports, working papers, and bibliographies that contain minimal annotation. Does not contain extensive analysis.

- CONTRACTOR REPORT. Scientific and technical findings by NASA-sponsored contractors and grantees.

- CONFERENCE PUBLICATION. Collected papers from scientific and technical conferences, symposia, seminars, or other meetings sponsored or cosponsored by NASA.

- SPECIAL PUBLICATION. Scientific, technical, or historical information from NASA programs, projects, and missions, often concerned with subjects having substantial public interest.

- TECHNICAL TRANSLATION. Englishlanguage translations of foreign scientific and technical material pertinent to NASA's mission.

Specialized services also include creating custom thesauri, building customized databases, organizing and publishing research results.

For more information about the NASA STI program, see the following:

- Access the NASA STI program home page at http://www.sti.nasa.gov

- E-mail your question via the Internet to help@ sti.nasa.gov

- Fax your question to the NASA STI Help Desk at 301-621-0134

- Telephone the NASA STI Help Desk at 301-621-0390

- Write to: NASA Center for AeroSpace Information (CASI) 7115 Standard Drive Hanover, MD 21076-1320 


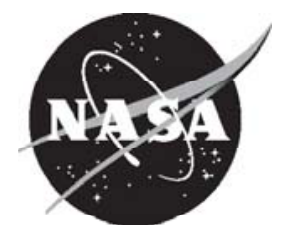

\title{
Wave Propagation Through Inhomogeneities With Applications to Novel Sensing Techniques
}

\author{
G. Adamovsky, R. Tokars, and D. Varga \\ Glenn Research Center, Cleveland, Ohio \\ B. Floyd \\ Sierra Lobo, Inc., Cleveland, Ohio
}

Prepared for the

46th Aerospace Sciences Meeting and Exhibit

sponsored by the American Institute of Aeronautics and Astronautics

Reno, Nevada, January 7-10, 2008

National Aeronautics and

Space Administration

Glenn Research Center

Cleveland, Ohio 44135 


\section{Acknowledgments}

The work was supported by the Hypersonics Project under the NASA's Fundamental Aeronautics Program.

This work was sponsored by the Fundamental Aeronautics Program at the NASA Glenn Research Center.

Level of Review: This material has been technically reviewed by technical management.

Available from

NASA Center for Aerospace Information 7115 Standard Drive

Hanover, MD 21076-1320
National Technical Information Service 5285 Port Royal Road Springfield, VA 22161 


\title{
Wave Propagation Through Inhomogeneities With Applications to Novel Sensing Techniques
}

\author{
G. Adamovsky, R. Tokars, and D. Varga \\ National Aeronautics and Space Administration \\ Glenn Research Center \\ Cleveland, Ohio 44135 \\ B. Floyd \\ Sierra Lobo, Inc. \\ Cleveland, Ohio 44135
}

\begin{abstract}
The paper describes phenomena observed as a result of laser pencil beam interactions with abrupt interfaces including aerodynamic shocks. Based on these phenomena, a novel flow visualization technique based on a laser scanning pencil beam is introduced. The technique reveals properties of light interaction with interfaces including aerodynamic shocks that are not seen using conventional visualization. Various configurations of scanning beam devices including those with no moving parts as well as results of "proof-of-concept" tests are included.
\end{abstract}

\section{Introduction}

Effects of propagation of light through gases with variations in their density have been known and used in ground wind tunnels and other aerodynamic test facilities. The variations, known as density inhomogeneities, have been routinely detected and visualized by interferometers, Schlieren systems, and shadowgraphs (refs. 1 to 4 ).

Flow visualization techniques such as interferometric, Schlieren, and shadowgraphy usually involve a laser and a collimating lens that forms a nearly plane wave. The wave is sent through a transparent section of the test facility normal to the direction of the air flow. After passing through the transparent section of the facility, the plane wave is displayed on a screen or a charged-coupled device (CCD) array. If the air flow is homogeneous and the air density is constant everywhere inside the test section, the display is uniformly illuminated. If the flow contains density variations, the illumination of the display is not uniform any more but rather has dark and bright regions. The contrast of the resultant pattern depends on the strength of the density variations or the density gradient as well as the visualization technique used.

The traditional flow visualization techniques, despite their wide use, have significant shortcomings. First of all, the techniques are based on filling most of the window of the test section and require high power light sources and large optical components. Thus, they cannot be used in air- or space-borne systems without significant weight and real estate penalties. On the other hand, small and lightweight low power light sources in the conventional configuration do not generate a signal with a sufficient signal-tonoise ratio at the detector to achieve an adequate resolution. Secondly, the fact that the entire test section has to be illuminated masks the second order phenomena associated with the wave propagation through and interaction with inhomogeneities.

The shortcomings of conventional flow visualization techniques have motivated interests in development of alternative methods and further studies of processes associated with propagation of optical fields through inhomogeneities. 


\section{Wave Propagation of Optical Beams Through Inhomogeneities}

Inhomogeneity is a property of matter that changes in space, time, or both. We limit our discussion to inhomogeneities that occur in space and are time invariant. We will also limit the discussion to media that are transparent or semitransparent to electromagnetic radiation, specifically visible light.

Phenomena of light propagation through inhomogenous media have been described by the electromagnetic field theory expressed by the Maxwell equations and diffraction and scattering theories known from physics and optic (refs. 5 to 8). In view of these theories, any inhomogeneous medium has interfaces that separate regions with uniform refractive index. As light encounters the interfaces it experiences diffraction, scattering and other effects. The strength of the effects depends on a number of factors including the type of interface.

The interfaces could be abrupt, continuous, or mixed. Abrupt interfaces exhibit a jump in the refractive index. Surfaces of glass components in conventional optical systems represent such interfaces. In continuous interfaces the index of refraction changes gradually, or in a distributed fashion. The qualifying factor for this type of interface is that the observer never sees the homogeneous parts of the medium and, from the measurements, the medium is perceived to be continuously inhomogeneous. Representative examples of gradual or distributed interfaces are water in the ocean and the Earth atmosphere. Water in the ocean has a higher temperature at the surface than at the bottom and, as a result, a refractive index gradient. Variations in salinity also affect the refractive index of water. The Earth atmosphere has air density that varies with the altitude. Media with mixed interfaces have distinct areas where, for all practical purposes, they could be treated as homogeneous. The mixed interfaces, than, are characterized by width or thickness of inhomogeneous layers between homogeneous areas.

Each time an electromagnetic field encounters an obstacle it experiences scattering and diffraction. Very often diffraction is considered to be a case of scattering. The scattering pattern depends on three factors, the scatterer (its geometry, material, and surface quality), the incident electromagnetic field (wavelength, bandwidth, polarization, and geometry) and the location of the observer (screen, camera, etc.) It is outside of the scope of this paper to discuss in detail scattering and diffraction phenomena. Those interested in these topics may find relevant information elsewhere (refs. 9 and 10).

\section{Interaction of Optical Beams With Sharp Interfaces}

To study optical beams interaction with abrupt interfaces we used dielectric fibers and cylinders and placed them in the path of optical beams. Our experimental setup was a combination of two setups with different illuminating optical beams. Figures 1 and 2 show schematical arrangements of the setups with the first setup using a relatively large diameter (about $5 \mathrm{~mm}$ ) collimated optical beam and the second one employing a HeNe laser that emits a Gaussian beam with about $0.5 \mathrm{~mm}$ diameter at the laser exit aperture.

In the setup shown in figure $1 \mathrm{a}$ large diameter incident beam is generated by light emitted from the tip of a single mode fiber placed in the focal plane of a collimating lens. A remotely located laser serves as an initial light source.

The beam emitted from the laser shown in figure 2 has a Gaussian profile meaning that its diameter increases with the distance. Also, for the purpose of collimating a narrow Gaussian beam, a laser beam collimator (shown in a broken line) is incorporated in the path after a beam splitter. The arrangement permits propagation of both narrow Gaussian laser beams, an expanding Gaussian laser beam and a collimated one, without changes in the rest of the setup.

Both setups shown in figures 1 and 2 are combined in one. In the combined setup both beams, a narrow Gaussian laser beam and the large diameter collimated one, have a common path from the beam splitter to the screen. Such an arrangement permits a compatibility of setups and consistency in measurements.

The optical beams strike fibers and cylinders normally to their respective long axis. In all cases the dielectric fibers and cylinders act as scatters and the observed scattering patterns are observed and recorded. 


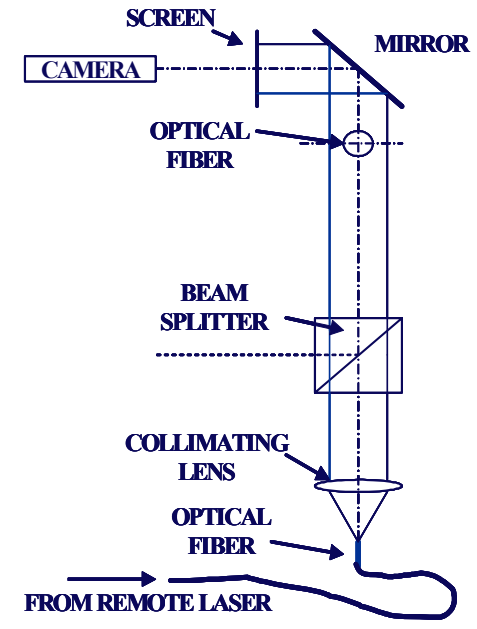

Figure 1. Experimental setup employing a large diameter collimated optical beam.

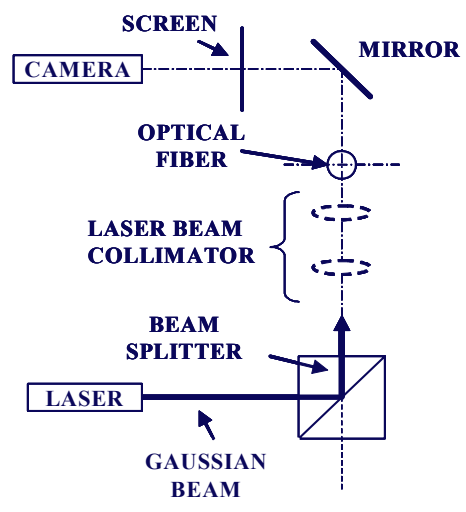

Figure 2. Experimental setup using a narrow Gaussian laser beam.

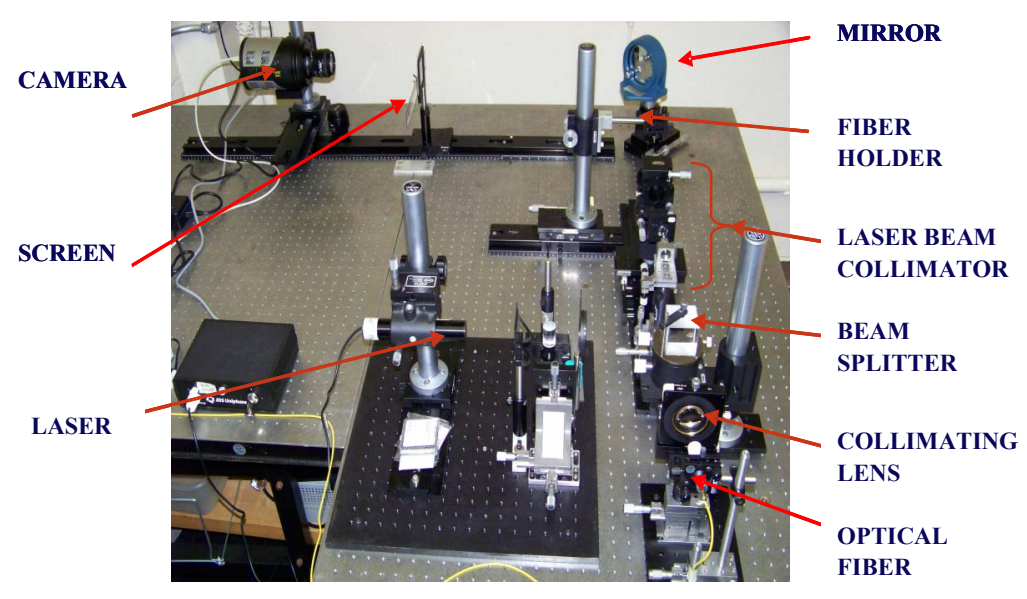

Figure 3. Photograph of one of configurations of the combined experimental setup.

Figure 3 shows a photograph of one of configurations of the combined experimental setup with an optical fiber as a diffractive element. During the experiment the beams are used independently where each of the beams travels its own path. Moreover, when one of the beams is used, the other one is blocked. A scattering element, a fiber or a cylinder, is placed in the common path for both beams and the scattered light is observed on the screen. The common path between the optical fiber and the screen is about $485 \mathrm{~mm}$ long. The fiber holder, designed to accommodate optical fibers of different diameters, is placed on a translation stage (not identified in the figure). The laser beam collimator is used only with the Gaussian beam from the laser.

We used, as scatterers, glass fibers with outer diameters 125 and $240 \mu \mathrm{m}$. First, we put optical fibers in the configuration setup as in figure 1 and recorded images of patterns generated on the screen. The results along with an image of unobstructed beam are shown in figure 4 . The images in figure 4 were obtained by replacing the screen in figure 1 with a beam viewing camera which provided a direct recording of patterns of scattered light. A characteristic dip in the middle of images obtained with fibers suggests the presence of a typical shadowgraph visualization phenomenon. 

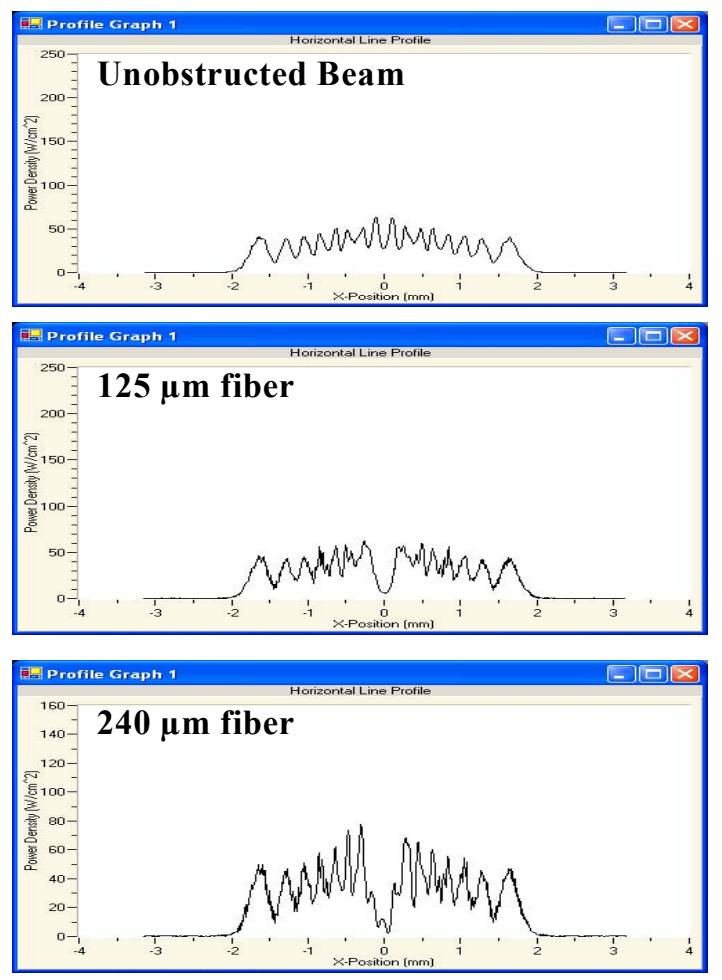

Figure 4. Patterns obtained by a large diameter collimated optical beam striking 125 and $240 \mu \mathrm{m}$ diameter optical fibers.

When the diameter of the incident beam gets smaller the patterns become significantly different. Figures 5 and 6 depict patterns generated as a result of narrow laser beams interaction with fibers and observed on the screen. The patterns are obtained by placing the fibers in the setup as shown in figure 2 at the distance approximately $890 \mathrm{~mm}$ from the exiting aperture of the laser. Figure 5 shows scattering patterns generated by a $1.5 \mathrm{~mm}$ diameter collimated Gaussian beam on 125 and $240 \mu \mathrm{m}$ diameter optical fibers as well as an image of the unobstructed beam. Figure 6 shows intensity distributions for cases similar to those presented in figure 5 with the incident beam being a noncollimated Gaussian. In the plane where the optical fibers are located that laser beam has a diameter of approximately $2.7 \mathrm{~mm}$.

It is obvious from figures 4, 5, and 6 that interaction of a small diameter laser pencil beam with thin obstacles is accompanied by formation of patterns different from conventional shadowgraphs. Figures 5 and 6 show an increase in the dimension of the scattered pattern compared with the dimension of the unobstructed beam and formation of multiple spots. The increase is visibly larger in the case of a smaller diameter collimated beam. The patterns in figure 6 are close to those theoretically predicted by others (ref. 11).

The setup shown in figure 2 was also used to investigate scattering of narrow laser beams from cylindrical surfaces. In this experiment the fiber was replaced by a 0.5 in. diameter plastic cylinder with polished cylindrical surface. The incident laser beam was sent at a grazing angle to the surface of the cylinder normal to its main axis as shown in figure 7 . The image of the unobstructed beam is given on the same figure to the right. 

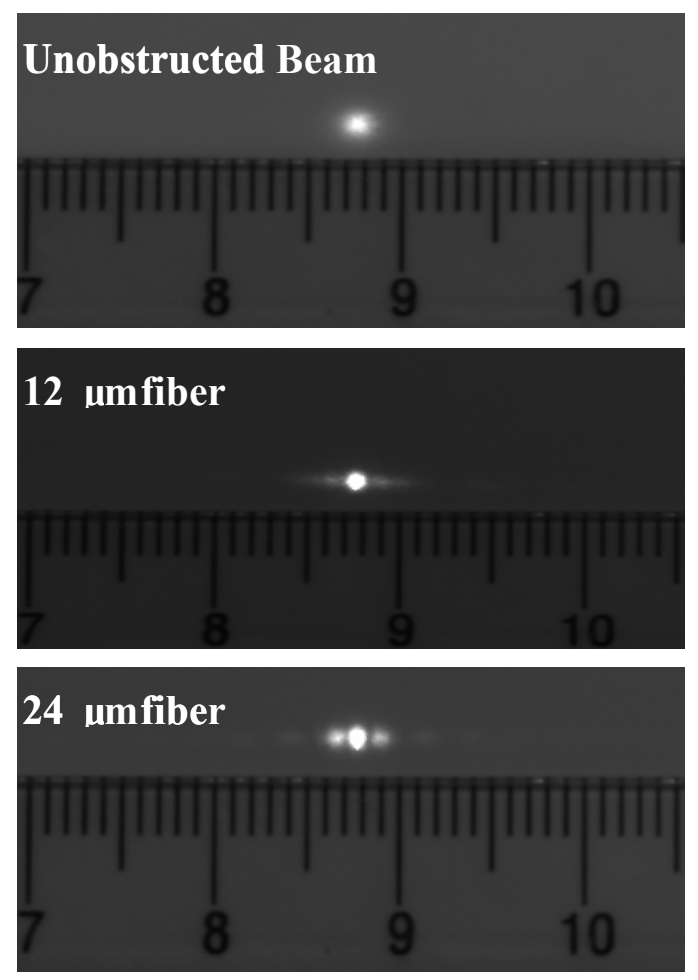

Figure 5. Diffraction of $1.5 \mathrm{~mm}$ diameter narrow collimated Gaussian beam on 125 and $240 \mu \mathrm{m}$ diameter optical fiber.
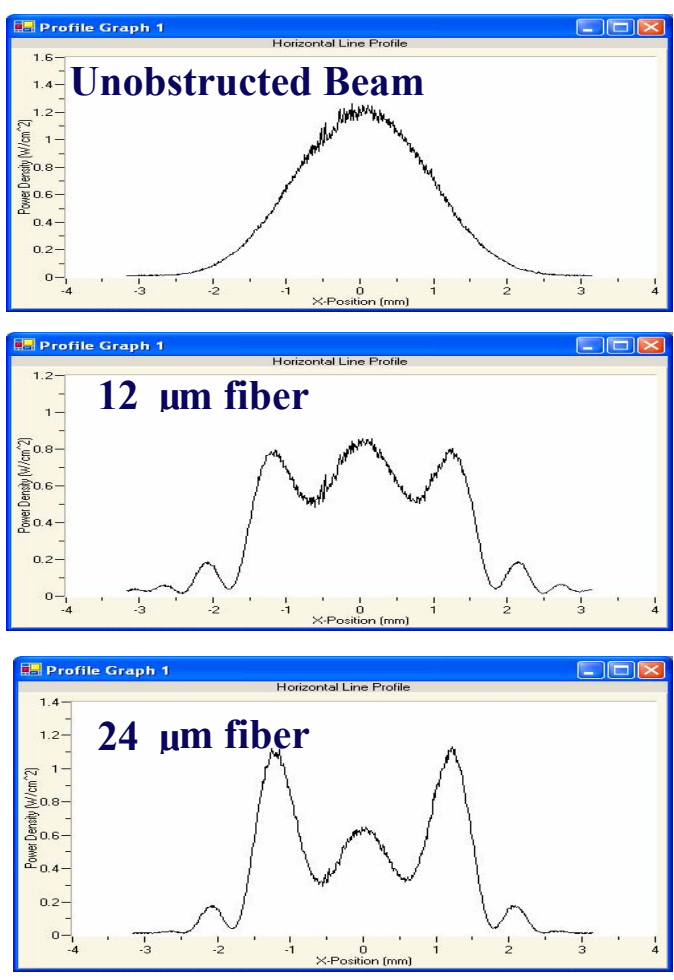

Figure 6. Diffraction of a non=collimated Gaussian beam on 125 and $240 \mu \mathrm{m}$ diameter optical fibers.
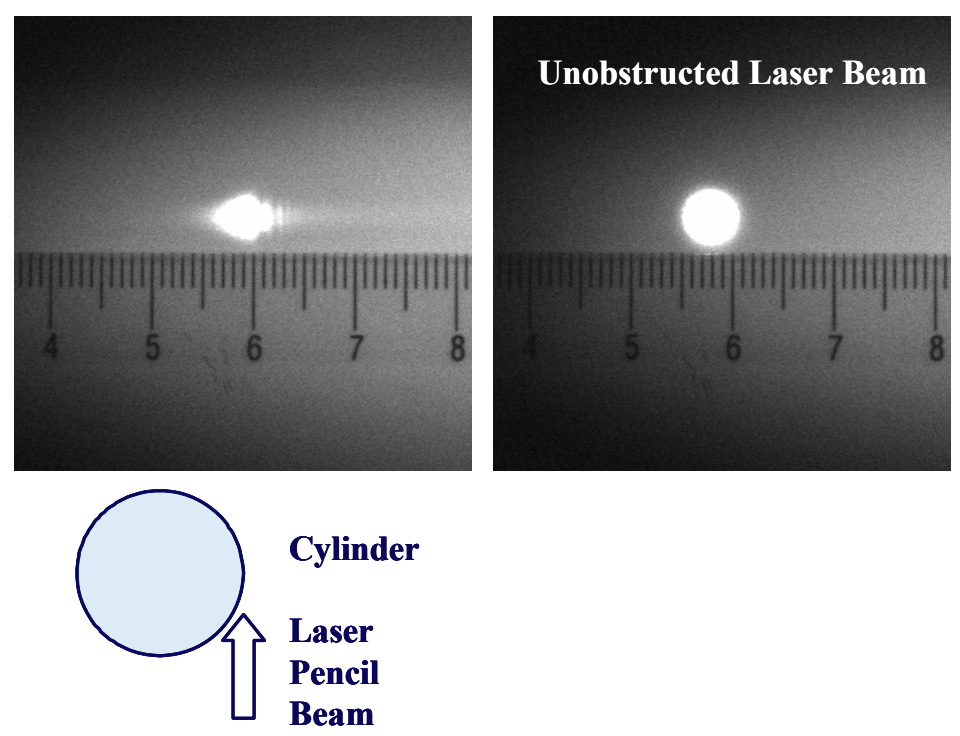

Figure 7. Schematics of a laser pencil beam striking a cylindrical surface and the observed pattern. Image of an unobstructed beam is given for comparison to the right. 


\section{Laser Pencil Beam Propagation Through Airflow With Aerodynamic Shocks}

Aerodynamic shocks belong to mixed type of interfaces and the shock thickness is one of the shock parameters defined as a distance over which the change in air density and the corresponding change in the refractive index occur. Among various models used to determine the value of refractive index across a shock as a function of position $x$ one of the most frequently used is (refs. 12 and 13)

$$
n(x)=n_{\text {low }}+\frac{\Delta n}{1+\exp \left(-4 \frac{x}{L}\right)}
$$

where, $\Delta n$ is the jump in the refractive index across the shock, $\Delta n=n_{\text {high }}-n_{\text {low }}$,

$n_{\text {high }}$ and $n_{\text {low }}$ are maximum and minimum values of the refractive index respectively across the shock, $L$ is the shock thickness.

Experimental measurements of shock front thickness in various gasses have shown that their values are small enough to consider the shocks to be abrupt interfaces (refs. 12 to 14).

As was previously mentioned, every time light interacts with an abrupt inhomogeneity, it diffracts, scatters, and forms interference patterns. Effects associated with propagation of both, large diameter and laser pencil beams, through aerodynamic shocks are similar to those described in the previous section. The difference however lies is the fact that in case of aerodynamic shocks the change in refractive indexes is very small and could be of the order of $10^{-3}$ depending on pressures on both sides of the shock. The large beam propagation case results in conventional shadowgraph images of shocks. However, closer analysis reveals other effects, such as, for instance, light interference on bow shocks. Furthermore, splitting of a pencil beam by a bow shock has also been observed and reported. The phenomena of light interference on a bow shock and splitting of a pencil laser beam by a shock are shown in figures 8 and 9 , respectively (refs. 15 and 16).

Experiments with laser beams passing through shocks have also been conducted in aerodynamic tunnels and the result have shown that after passing through a shock the diameter of a laser pencil beam significantly increases (ref. 17). Figure 10 adopted from reference 17 exhibits three curves out of which the one drawn by a solid line represents the diameter of the beam after passing through a shock. The other two drawn by dotted lines represent cases when the laser beam is either upstream or downstream of the shock.
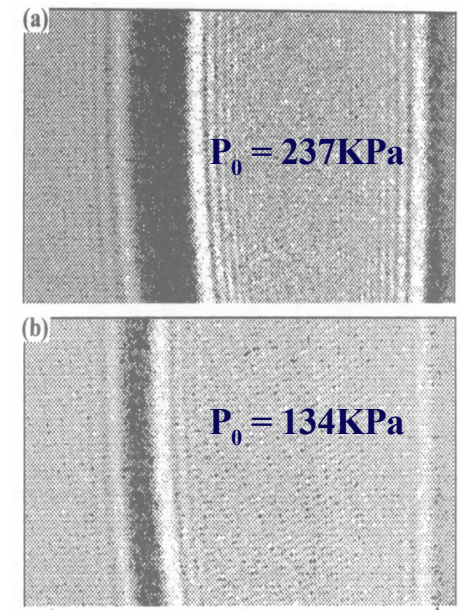

Figure 8. Interference of a laser beam on a bow shock for different free-stream total pressure $P_{0}$ and a fixed Mach number (adopted from Ref. 16 ).

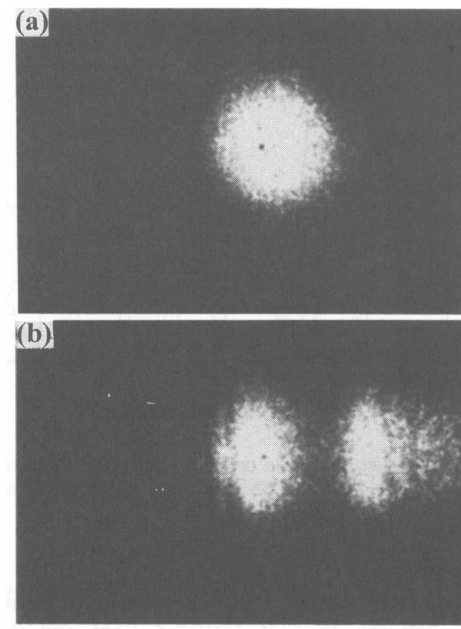

Figure 9. Splitting of a laser pencil beam by a bow shock (adopted from Ref. 16 ).

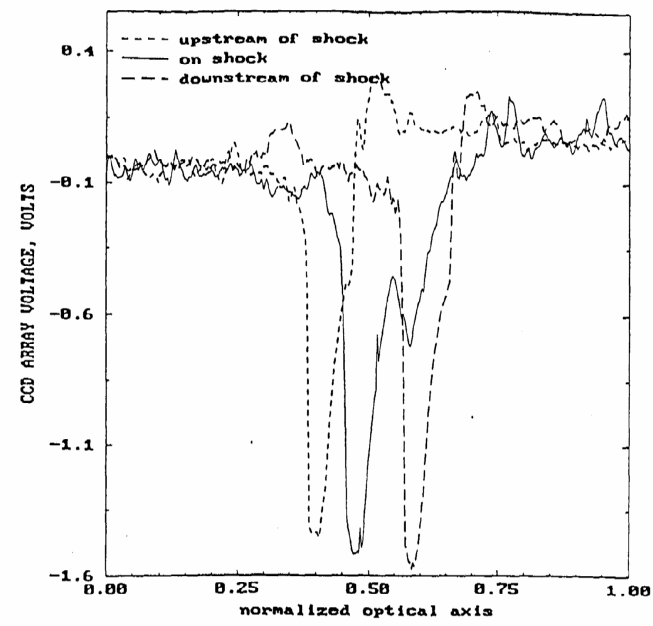

Figure 10. Images of a laser pencil beam upstream, downstream, and on the shock as seen by a CCD array (adopted from Ref. 17). 


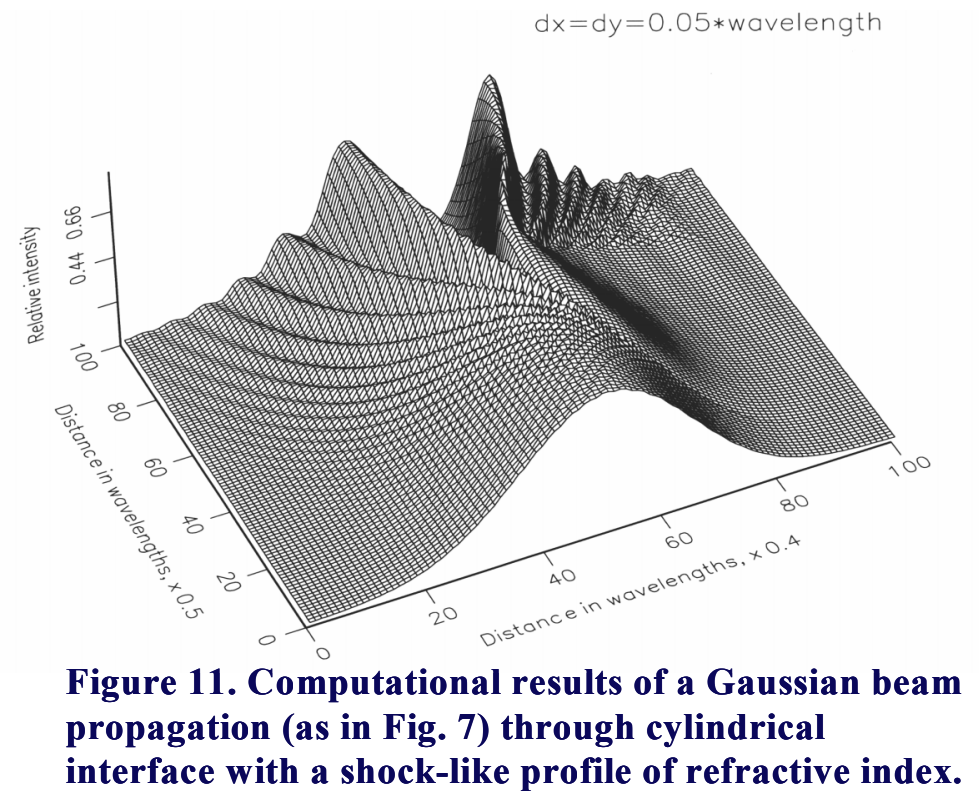

Modeling and computational analysis of a Gaussian beam propagation through inhomogeneities with shock like profiles have also been conducted using the Finite-Difference Time-Domain (FDTD) method (ref. 18) as a computational tool. The FDTD method has been described in the literature elsewhere (refs. 19 to 22). The analysis also reveals splitting of a Gaussian beam and formation of interference fringes. In the model the relative position of the abrupt interface and the incident Gaussian laser beam are similar to those shown in figure 7. Results of computations with $n_{\text {low }}=1.0$ and $\Delta n=0.01$ are shown in figure 11.

As is seen from figures 9 and 11 there is a similarity in patterns observed experimentally and achieved computationally.

\section{Flow Visualization Using Laser Pencil Beams}

The capability of abrupt and nearly abrupt interfaces to split and distort narrow laser pencil beam has been utilized in a scanning beam flow visualization concept. The concept has several advantages over conventional flow visualization techniques. First of all, in a conventional shadowgraph the light from a light source is delivered to the area where flow inhomogeneities are formed and is spread forming a large diameter collimated beam that fills the entire area of interest. Because the technique requires high power lasers and large optical components it cannot be used in on-board systems without significant weight and real estate penalties. On the other hand, small and lightweight low power sources in the conventional configuration do not generate a signal with a sufficient signal-to-noise ratio at the detector to achieve an adequate resolution. Secondly, the fact that the entire test section has to be illuminated masks the second order phenomena associated with the wave propagation through inhomogeneities.

To increase the signal to noise ratio of the detection systems without increase in the laser power we have introduced a novel flow visualization concept that involves a small diameter scanning pencil beam. In the process of passing through a test section the scanning beam generates a pattern that may be observed or recorded in a timely fashion. A laser used for this purpose has relatively low yet sufficient power to make the changes in the pattern detectable.

In addition, the pencil beam scanning technique permits observation of light diffraction and scattering from inhomogeneities. We have observed and reported diffraction of a nearly plane wave from a bow shock, as well as splitting of the laser pencil beam and formation of secondary peaks. Observations of these phenomena have been enabled by the narrow pencil beam. Also, weak secondary phenomena, such as the scattering and diffraction, occur outside of the boundaries of the incident pencil beam and are easily visible against a dark background. 


\section{Scanning Mode Sensor}

One of the ways to scan optical beams is to employ electromechanical means in either a linear or angular fashion as demonstrated in figure 12. An electromechanical scanning system has either a translating or rotating mirror that moves the incoming laser beam across a test section where shocks are expected. In case of angular scanning a rotating mirror is incorporated and its axis of rotation is placed at the reflecting surface of the mirror. A lens is also added and positioned in such a way that its focal point lies on the rotational axis of the mirror. Thus, the incident laser beam, after reflection from the rotating mirror, translates through the test section perpendicularly to the direction of the air flow.

A problem with electromechanical scanners is that they require electrical power to operate mirrors. A spectral scanner is free of these shortcomings. The spectral scanning concept is illustrated in figure 13.

The main components in spectral scanners are a tunable light source and an optical dispersive element (ref. 23). Examples of dispersive elements are dispersive prisms and diffraction gratings. The tunable light source generates a narrow pencil beam of light whose optical frequency or wavelength changes in time in prescribed manner. A controller monitors the light emitted by the tunable light source and insures its timely emission at a prescribed sequence. After interaction with a stationary dispersive element the direction of the light beam changes depending on the optical frequency of the light. This space-frequency or space-wavelength scanning generates a "rainbow" with the difference that each "color" appears in its place at a given time.

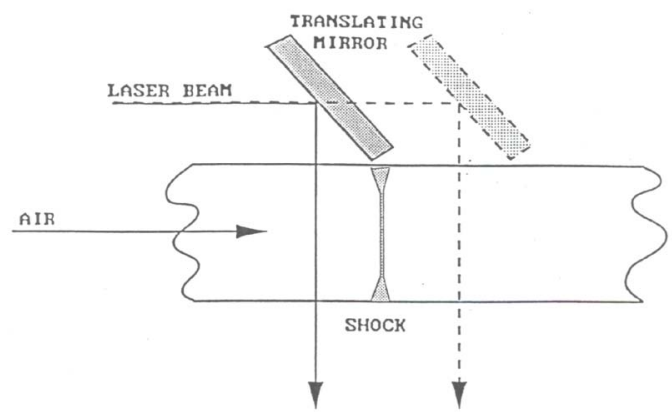

a) LINEAR SCANNING

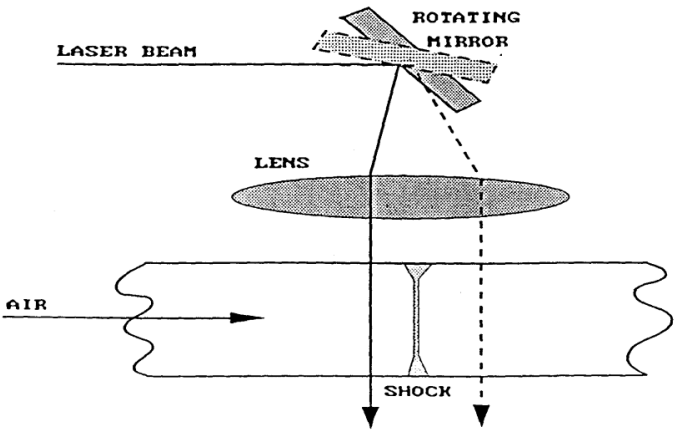

b) ANGULAR SCANNING

Figure 12. Examples of electromechanical scanning: a) linear and b) angular.

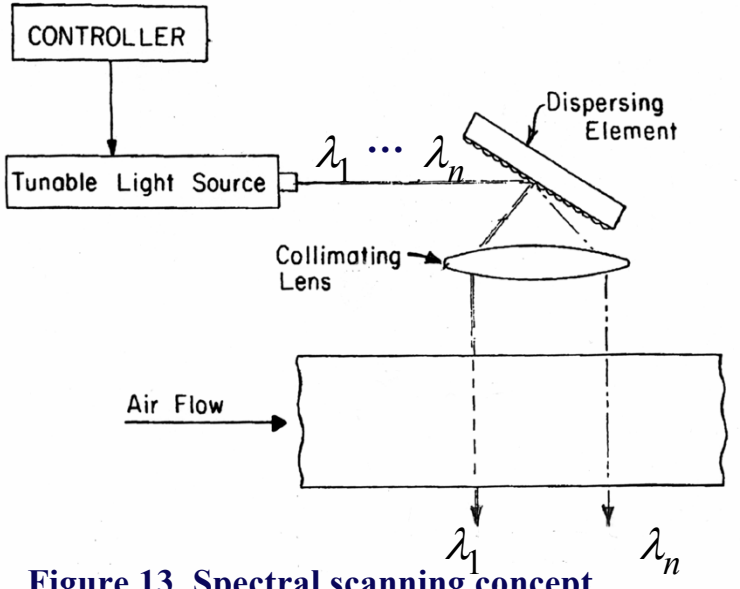

Figure 13. Spectral scanning concept 
The pencil laser beam may contain several individual beams with different optical frequencies (wavelengths). Thus, the stationary dispersive element produces several "rainbows". In the spectral scanner the optical dispersive element is positioned at the focal point of the collimating lens.

\section{Demonstration of Spectral Scanning}

The experimental arrangement used to demonstrate operation of a spectral scanner is depicted in figure 14 (ref. 24). A bow shock is generated by air impinging on a blunt body. A tunable laser, a diffraction grating, and a collimating lens are assembled as explained in the previous section such that beams exiting the lens remain parallel to each other and normal to the direction of the air flow.

Results of the experiment are presented in figure 15. The top row displays pictures of laser beam profiles at two wavelengths without air sent through the system. The bottom row has the beam profiles at the same wavelengths with the beam missing the shock at one wavelength (left picture) and hitting the shock at the other wavelength (right picture). The wavelengths are shown above the corresponding pictures. A CCD array was used to obtain the pictures. The left column contains shadowgraph images of the setup without the air flow (top) and with a shock producing air flow (bottom).

\section{Applications to Aerospace}

One of main applications of the scanning beam flow visualization technique is in-flight detection and monitoring of shocks including normal shocks generated in a mixed compression supersonic inlet.

The need for shock position sensors capable of meeting flight qualifying requirements has been recognized (refs. 25 and 26) and attempts have been made to develop such sensors (refs. 27 and 28). Early efforts were concentrated around using pressure taps along the inlet walls. The positions of the shocks were determined by tracking the pressure reading and locating the pressure jump associated with the shock. This basic technique evolved in several wall pressure-based configurations of normal shock position sensing systems. Despite apparent initial success, these wall pressure-based measuring techniques have serious drawbacks. The most important drawbacks are slow response due to pneumatic manifolds used and the effect of the boundary layer on the stability of pressure readings. These problems seriously restrict applicability of these techniques to normal shock detection and control during supersonic flight.

Moreover, for a commercial aircraft, economic efficiency has to be achieved in order to make supersonic flight economically viable. As a result, the control system is required, in addition to avoiding an un-start, to provide the most economical operating regime for the engine (achieved by minimizing the fuel consumption).

Optical flow analyzing methods do not have problems of the wall pressure-based measuring techniques and optical flow visualization is widely used in ground-based flow analyzing facilities. Among basic flow visualization techniques, interferometry, Schlieren, and shadowgraph, the shadowgraph is the most suitable for shock detection. It is because patterns generated by the technique represent the second

order derivatives of the density distribution, and the shocks which are being created by very rapid changes in air densities are observed best by the shadowgraph.

A scanning optical pencil beam of a shock sensor, because of its advantages, has a great potential of replacing conventional schadowgraph. 


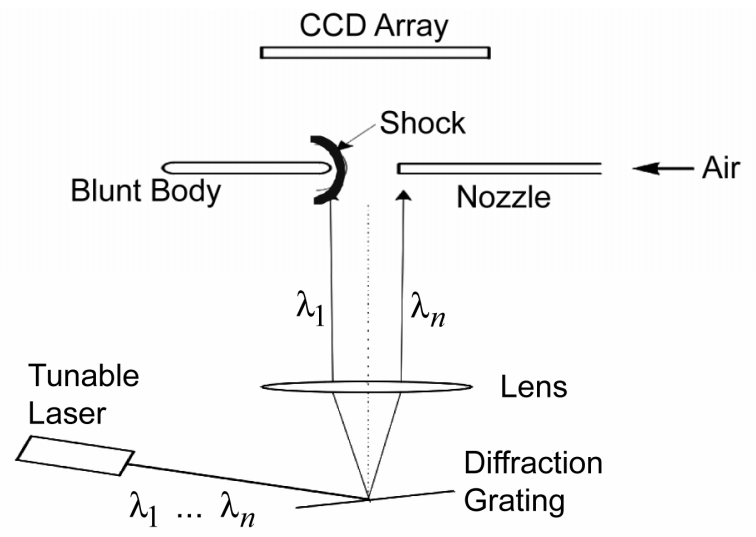

Figure 14. Scanning mode sensor demonstration setup.
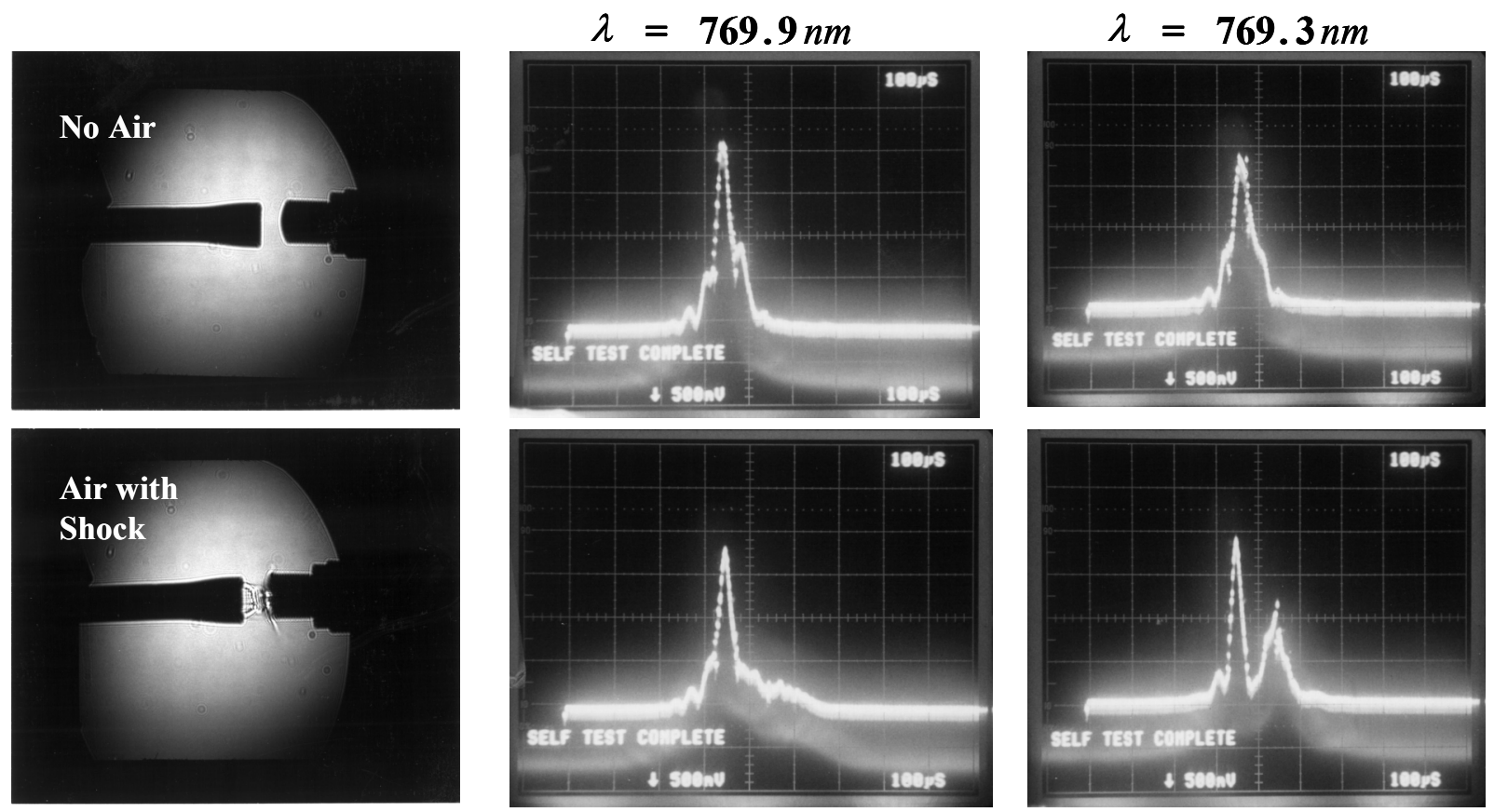

Figure 15. Observations of a shock by a CCD array using a spectral scanning arrangement as in Fig. 14. Top Row: Laser beam profiles at two wavelengths without air sent through the system.

Bottom Row: Laser beam profiles at the same wavelengths with the beam missing the shock at one wavelength (left picture) and hitting the shock at the other wavelength (right picture).

The wavelengths are shown above the corresponding pictures. Pictures to the left show images of the setup without the air flow (top) and with a shock producing air flow (bottom). 


\section{Conclusion}

We have introduced a novel flow visualization concept that involves a small diameter scanning beam. In the process of passing through a test section the scanning beam generates a pattern that is observed or recorded in a timely fashion. A laser used for this purpose has relatively low yet sufficient power to make the changes in the pattern detectable.

In addition, the pencil beam scanning technique permits observation of light diffraction and scattering on inhomogeneities. We have observed and reported diffraction of a nearly plane wave on a bow shock, as well as splitting of the laser pencil beam and formation of secondary peaks. Observations of these phenomena have been enabled by the narrow pencil beam. Also, weak secondary phenomena, such as the scattering and diffraction, occur outside of the boundaries of the incident pencil beam and are well visible on a dark background.

\section{References}

1. Beams, J.W., "Shadow and Schlieren Methods," Physical Measurements in Gas Dynamics and Combustion, R.W. Ladenburg, B. Lewis, R.N. Pease, and H.S. Taylor, eds., Princeton University Press, Princeton, New Jersey, 1954, pp. 26-46.

2. Merzkirch W., Flow Visualization, 2nd ed., Academic Press, Orlando, Florida, 1987.

3. Howes, W.L. and Buchele, D.R., "Optical Interferometry in Inhomogeneous Gasses," J. Opt. Soc. A., vol. 56, no. 11, 1966, pp. 1517-1528.

4. Hariharan, S.I. and Johnson, D. K., "Transmission of Light Waves Through Normal Shocks," Appl. Opt., vol. 34, no. 33, 1995, pp. 7752-7758.

5. Felsen, L.B. and Marcuvitz, N., Radiation and Scattering of Waves, IEEE PRESS Series on Electromagnetic Waves, IEEE, New York, 1994.

6. Chew, W.C., Waves and Fields in Inhomogeneous Media, Van Nostrand Reinhold, 1990, New York.

7. Gaskill, J.D., "The Propagation and Diffraction of Optical Wave Fields," Linear Systems, Fourier Transforms, and Optics, John Wiley \& Sons, New York, 1978, Chapter 10.

8. Born, M. and Wolf, E., Principles of Optics, 6th Edition, Pergamon Press, 1980.

9. Kerker, M., The Scattering of Light and Other Electromagnetic Radiation, Academic Press, London, 1969.

10. Newton, R.G., Scattering Theory of Waves and Particles, McGraw-Hill, New York, 1966, Parts I, II.

11. Ganci, S., "Fraunhofer Diffraction by a Thin Wire and Babinet's Principle," Am. J. Phys., vol. 73, no. 1, January 2005, pp. 83-84.

12. Cowan, R.G. and Hornig, D.F., "The Experimental Determination of the Thickness of a Shock Front in a Gas," J. Chem. Phys., vol. 18, no. 8, 1950, pp. 1008-1018.

13. E.F. Greene, E.F., Cowan, R.G., and Hornig, D.F., "The Thickness of Shock Fronts in Argon and Nitrogen and Rotational Heat Capacity Lags," J. Chem. Phys., vol. 19, no. 4, 1951, pp. 427-434.

14. Hornig, D.F, "Shock Front Measurements by Light Reflectivity," Physical Measurements in Gas Dynamics and Combustion, Section E, R.W. Ladenburg, B. Lewis, R.N. Pease, and H.S. Taylor, eds., Princeton University Press, Princeton, New Jersey, 1954, Section E.

15. Panda, J. and Adamovsky, G., "Laser Light Scattering by Shock Waves," Physics of Fluids, vol.7, no. 9, 1995, pp. 2271-2279.

16. Panda, J. and Adamovsky, G., "An Experimental Investigation of Laser Light Scattering by Shock Waves," 33rd AIAA Aerospace Science Meeting and Exhibit (January 9-12, 1995, Reno, Nevada), Paper no. AIAA-95-0518.

17. Adamovsky, G. and Johnson, D.K., "Optical Techniques for Shock Visualization and Detection," Optical Techniques in Fluid, Thermal, and Combustion Flows, S.S. Cha and J.D. Trolinger, eds., SPIE Proceedings, vol. 2546, 1995, pp. 348-357.

18. Adamovsky, G. and Ida, N., "Laser Beam Propagation Through Inhomogeneous Media With ShockLike Profiles: Modeling and Computing," Optical Technology in Fluid, Thermal, and Combustion 
Flow III," S.S. Cha, J.D. Trolinger, and M. Kawahashi, eds., SPIE Proceedings, vol. 3172, 1997, pp. 530-539.

19. Taflove, A. and Umashankar, K.R., "The Finite-Difference Time-Domain Method for Numerical Modeling of Electromagnetic Wave Interaction With Arbitrary Structures," Finite Element and Finite Difference Methods in Electromagnetic Scattering, M.A. Morgan, ed., PIER 2, Progress in Electromagnetic Research, Elsevier, New York, 1990, pp. 287-373.

20. Taflove, A., Computational Electrodynamics: The Finite-Difference Time-Domain Method, Artech House, Boston, 1995.

21. Taflove, A., "Review of the Formulation and Applications of the Finite Difference Time-Domain Method for Numerical Modeling of Electromagnetic Wave Interactions With Arbitrary Structures," Wave Motion, vol. 10, 1988, pp. 547-582.

22. Kunz K.S. and Luebbers, R.J., The Finite Difference Time Domain Method in Electromagnetics, CRC Press, Boca Raton, Florida, 1993.

23. Adamovsky, G. and Giles, S., Jr., "Laser Pencil Beam Based Techniques for Visualization and Analysis of Interfaces Between Media," NASA TM-206635, 1998.

24. Adamovsky, G.: "Scanning Mode Shock Position Sensor Invented and Demonstrated," Research \& Technology 1998, NASA/TM-1999-208815, 1999, p. 58.

25. Hewett, M.D., "High-Speed Civil Transport Issues and Technology Program," NASA CR-186020, 1992.

26. Ray, J.K., Carlin, C.M., and Lambregts, "High-Speed Civil Transport Flight-Propulsion-Control Technological Issues," NASA CR-186015, 1992.

27. Saiben, M., Donovan, J.F., and Morris, M.J., "Flight Prototype Normal Shock Sensor," NASA CR18520, 1990.

28. Iverson, D.G., Jr., and Daiber, T.D., "Flight Prototype Normal Shock Position Sensor," NASA CR185204, 1989. 


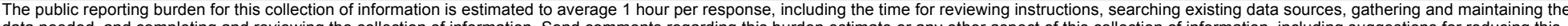

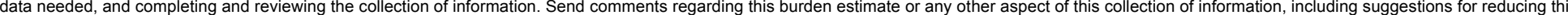

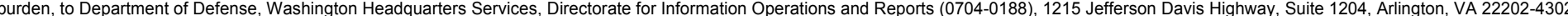

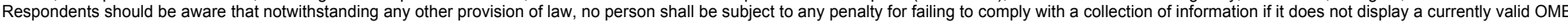
control number.

PLEASE DO NOT RETURN YOUR FORM TO THE ABOVE ADDRESS.
1. REPORT DATE (DD-MM-YYYY)
2. REPORT TYPE
3. DATES COVERED (From - To)

01-06-2008

Technical Memorandum

\section{TITLE AND SUBTITLE}

Wave Propagation Through Inhomogeneities With Applications to Novel Sensing Techniques

\section{5a. CONTRACT NUMBER}

5b. GRANT NUMBER

5c. PROGRAM ELEMENT NUMBER

5d. PROJECT NUMBER

6. AUTHOR(S)

Adamovsky, G.; Tokars, R.; Varga, D.; Floyd, B.

5e. TASK NUMBER

5f. WORK UNIT NUMBER

WBS 599489.02.07.03.06.02.01

\section{PERFORMING ORGANIZATION NAME(S) AND ADDRESS(ES)}

National Aeronautics and Space Administration

8. PERFORMING ORGANIZATION REPORT NUMBER

John H. Glenn Research Center at Lewis Field

E-16429

Cleveland, Ohio 44135-3191

9. SPONSORING/MONITORING AGENCY NAME(S) AND ADDRESS(ES)

National Aeronautics and Space Administration

Washington, DC 20546-0001

10. SPONSORING/MONITORS
ACRONYM(S)
NASA
11. SPONSORING/MONITORING
REPORT NUMBER
NASA/TM-2008-215185; AIAA-2008-255

\section{DISTRIBUTION/AVAILABILITY STATEMENT}

Unclassified-Unlimited

Subject Categories: 06 and 19

Available electronically at http://gltrs.grc.nasa.gov

This publication is available from the NASA Center for AeroSpace Information, 301-621-0390

\section{SUPPLEMENTARY NOTES}

\section{ABSTRACT}

The paper describes phenomena observed as a result of laser pencil beam interactions with abrupt interfaces including aerodynamic shocks. Based on these phenomena, a novel flow visualization technique based on a laser scanning pencil beam is introduced. The technique reveals properties of light interaction with interfaces including aerodynamic shocks that are not seen using conventional visualization. Various configurations of scanning beam devices including those with no moving parts, as well as results of "proof-of-concept" tests, are included.

\section{SUBJECT TERMS}

Sensing; Sensors; Shocks; Scanning; Scanners; Flow; Visualization

\section{SECURITY CLASSIFICATION OF:}

a. REPORT

$\mathrm{U}$

\section{LIMITATION OF} ABSTRACT

UU

18. NUMBER
OF
PAGES
18

19a. NAME OF RESPONSIBLE PERSON

STI Help Desk (email:help@sti.nasa.gov)

19b. TELEPHONE NUMBER (include area code) $301-621-0390$ 

